\title{
Thermal Conductivity and Microstructure Properties of Porous SiC Ceramic Derived from Silicon Carbide Powder
}

\author{
Xiuwen $\mathrm{Wu}^{1,2^{*}}$, Hongwen $\mathrm{Ma}^{2,3}$, Xiaochao Chen ${ }^{1}$, Zhanbing $\mathrm{Li}^{1}$, Jie $\mathrm{Li}^{3}$ \\ ${ }^{1}$ National Laboratory of Mineral Materials, China University of Geosciences, Beijing, China; ${ }^{2}$ School of Science, China University of \\ Geosciences, Beijing, China; ${ }^{3}$ School of Materials Science and Technology, China University of Geosciences, Beijing, China. \\ Email: *wuxw2008@163.com
}

Received October $18^{\text {th }}, 2012$; revised November $18^{\text {th }}, 2012$; accepted November $28^{\text {th }}, 2012$

\begin{abstract}
Porous $\mathrm{SiC}$ ceramic were prepared with silicon carbide powder as the aggregate, silicone resin as the binder and pore agent by the process of mixing, iso-static pressure molding, and calcination. The mechanical properties and microstructures of the samples were characterized with a universal testing machine, X-ray diffraction, scanning electron microscope, and mercury injection. Two main factors, molding pressures and silicone resin mass ratio were studied in the experiments. The thermal conductivity of the samples was tested. The compressive strength was up to $19.4 \mathrm{MPa}$, and the porosities up to $30 \%$. The thermal conductivities, mainly influenced by porosities, increased from $0.68 \mathrm{~W} \cdot \mathrm{m}^{-1} \cdot \mathrm{K}^{-1}$ to $1.03 \mathrm{~W} \cdot \mathrm{m}^{-1} \cdot \mathrm{K}^{-1}$ with the porosity decreasing from $41.96 \%$ to $31.30 \%$.
\end{abstract}

Keywords: Porous Ceramic; Microstructure; Thermal Conductivity; SiC

\section{Introduction}

Porous $\mathrm{SiC}$ ceramic attracted much attention recently for their special structural properties, high strength and hardness, good mechanical properties and excellent chemical stability, particularly at high temperatures and hostile atmospheres. Porous $\mathrm{SiC}$ ceramic can be applied in many areas, such as for catalyst supports [1], hot gas or molten metal filters [2-4], high temperature membrane reactors [5], thermal insulating materials [6], gas sensors [7].

Many studies were about preparing porous $\mathrm{SiC}$ ceramic by different synthetic methods, or characterizing them on mechanical and structural properties. Dey et al. prepared porous $\mathrm{SiC}$ ceramic with good flexural strengths by an infiltration technique [8]. Bai et al. used $\mathrm{Fe}_{2} \mathrm{O}_{3}$ as pore-forming agent for preparation of $\mathrm{SiC}$ porous ceramic [9]. Maity et al. synthesized porous $\mathrm{SiC}$ with a mean fracture strength value of $303.9 \mathrm{MPa}$ from cellulosic bio-precursor [10]. Li et al. studied the influences of molding pressures, bonding phase contents, and $\mathrm{SiC}$ particle sizes on the flexural strength of SiC-based porous ceramic [3]. Thermal conductivity is a key factor for the application of porous $\mathrm{SiC}$ ceramic at high temperatures. But the thermal conductivity of porous $\mathrm{SiC}$ ceramic was less studied $[11,12]$.

Because thermal conductivity was affected by many factors, such as the sample porosity, microstructure, chemical composition, and manufacturing process, it is nec-

"Corresponding author essary to study the thermal conductivity of porous $\mathrm{SiC}$ ceramic. The focus of this manuscript is to prepare porous $\mathrm{SiC}$ ceramic with silicon carbide powder and silicone resin by the process of mixing, iso-static pressure molding, and calcinations. The microstructures, mchanical properties, and thermal conductivity of the samples were also studied.

\section{Materials and Methods}

\subsection{Preparation of Porous SiC Ceramic}

Green $\alpha$-SiC powders and DC249TM silicone resin were as the starting materials. The solvent for DC249 TM silicone resin was acetone. All the chemicals were supplied by the Beijing Chemical Reagents Company (China).

The SiC powders and DC249TM silicone resin with various mass ratios (100:0 - 47:3) were mixed with acetone solvent. And after stirring the mixture for $1 \mathrm{~h}$, the acetone was evaporated at $353 \mathrm{~K}$ for $24 \mathrm{~h}$ with a manual stirring every $6 \mathrm{~h}$. The above powders were ground to a particle size $75 \mu \mathrm{m}$ and then were pressed into cylindrical specimens (diameter $30.00 \mathrm{~mm}$, height $4.20 \mathrm{~mm}$ ) under $80-120 \mathrm{MPa}$. The specimens were fired in air at $1273 \mathrm{~K}$ for $2 \mathrm{~h}$, with a heating rate of $20 \mathrm{~K} \cdot \mathrm{min}^{-1}$.

\subsection{Characterization}

The phase analysis of the samples was performed by 
XRD (XD-3X diffraction meter, filtered $\mathrm{CuK} \alpha$ radiation, 20: $10^{\circ}-80^{\circ}$, scan step: $0.02^{\circ}$, scan rate: $8^{\circ} \mathrm{min}^{-1}$ ). The compressive strength was measured using an Instron1195 universal testing machine with a cross head speed of $1 \mathrm{~mm} \cdot \mathrm{min}^{-1}$. The microstructure was observed with a scanning electron microscope (SEM, JEOL JSM-6510A) at an acceleration voltage $10 \mathrm{kV}$. The pore distribution and average pore diameters of the samples were determined by mercury injection (AUTOSCAN-33). The thermal conductivity of the samples was measured with a thermal conductivity instrument (TC3000) made by the Xian Xiaxi company in China. The thermal conductivity of each sample was the average of three time measurements.

\section{Results and Discussion}

\subsection{Mechanical Properties}

The samples named SP0, SP2, SP4, and SP6 were prepared using $0: 100,1: 49,1: 24$, and 3:47 mass ratio of DC249TM silicone resin and SiC, respectively. The corresponding molding pressure was labeled after the sample name, such as SP0-80, meaning the molding pressure $80 \mathrm{MPa}$. The compressive strengths of the samples (Table 1) varied from 14.3 MPa to $19.4 \mathrm{MPa}$, and increased with increasing molding pressures, but decreased with increasing DC249TM silicone resin/SiC mass ratio. The compressive strength of porous $\mathrm{SiC}$ ceramics is mainly influenced by the porosity and the compositions. Chen et al. [13] reported the maximum compressive strength of $\mathrm{SiC}$ ceramic foam was only $2.48 \mathrm{MPa}$. The compressive strength of our samples (average 16.92 $\mathrm{MPa}$ ) was about 6.82 times of the $\mathrm{SiC}$ ceramic foam, mainly due to the different porosity of the $\mathrm{SiC}$ ceramic foam $(77 \%)$ and our samples (SP4-100 and SP6-100: average 35.76\%).

\subsection{Microstructures}

The phases of the samples SP2-80, SP4-80, and SP6-80 are $\beta$-SiC and quartz, detected by XRD in Figures 1-3. The change of DC249TM silicone resin/ $\mathrm{SiC}$ mass ratio did not cause obvious influence on the phases of the samples. The phases in our samples are in accordance with that given by Dey et al. [8]. But the quartz phase did not appeared, and the $\beta$-SiC phase was replaced by $4 \mathrm{H}-$ $\mathrm{SiC}$ and $6 \mathrm{H}-\mathrm{SiC}$ reported by Bai et al. [9], for a high sintering temperature at $2250^{\circ} \mathrm{C}$.

The SEM images of the samples SP2-100, SP4-100, and SP6-100 are shown in Figures 4-6. Scattered pores can be seen on the surfaces, and mainly inter granular pores. The pore diameters of inter granular pores are less than $20 \mu \mathrm{m}$, and the internal pores of the crystals about $2.0 \mu \mathrm{m}-2.5 \mu \mathrm{m}$.

Mercury injection results of SP4-100 and SP6-100 are
Table 1. Compressive strengths and thermal conductivities.

\begin{tabular}{ccccc}
\hline Sample & $P^{\mathrm{d}}(\mathrm{MPa})$ & Porosity $(\%)$ & $D^{\mathrm{e}}(\mu \mathrm{m})$ & $\lambda^{\mathrm{f}}\left(\mathrm{W} \cdot \mathrm{m}^{-1} \cdot \mathrm{K}^{-1}\right)$ \\
\hline SP0-80 & 17.2 & - & - & - \\
SP0-100 & 17.5 & 43.08 & 6.12 & - \\
SP0-120 & 18.4 & - & - & - \\
SP2-80 & 16.1 & - & - & 0.65 \\
SP2-100 & 17.4 & 41.75 & 5.59 & 0.70 \\
SP2-120 & 18.1 & - & - & 0.97 \\
SP4-80 & 16.8 & 41.96 & 5.66 & 0.68 \\
SP4-100 & 17.6 & 39.57 & 5.45 & 0.75 \\
SP4-120 & 19.4 & 31.30 & 5.21 & 1.03 \\
SP6-80 & 14.3 & - & - & 0.71 \\
SP6-100 & 15.0 & 31.95 & 5.27 & 0.93 \\
SP6-120 & 15.2 & - & - & 1.07 \\
\hline
\end{tabular}

${ }^{\mathrm{d}}$ Compressive strength; ${ }^{\mathrm{e}}$ Average pore diameter; ${ }^{\mathrm{f}}$ Thermal conductivity.

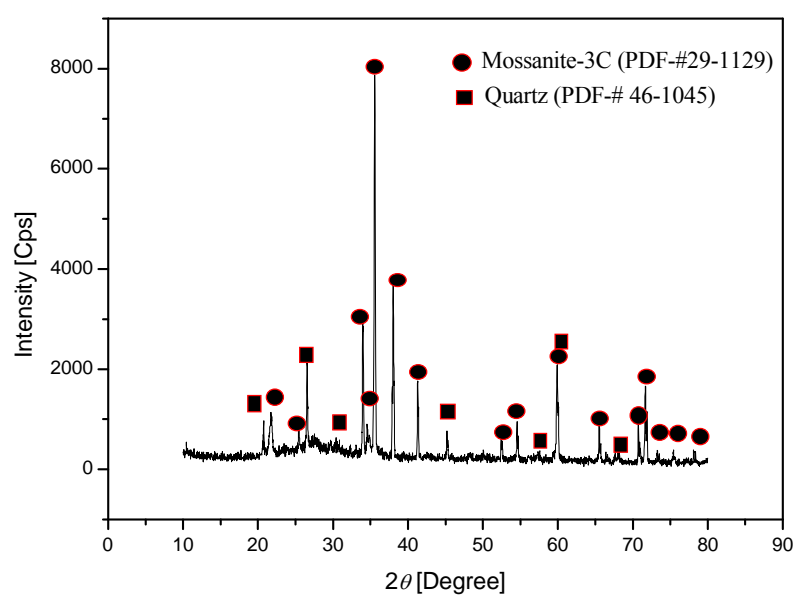

Figure 1. XRD pattern of SP2-80.



Figure 2. XRD pattern of SP4-80. 


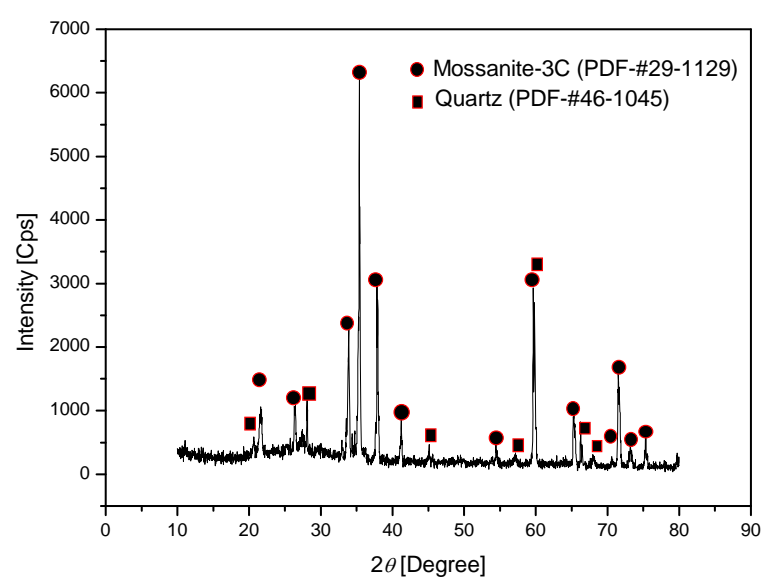

Figure 3. XRD pattern of SP6-80.
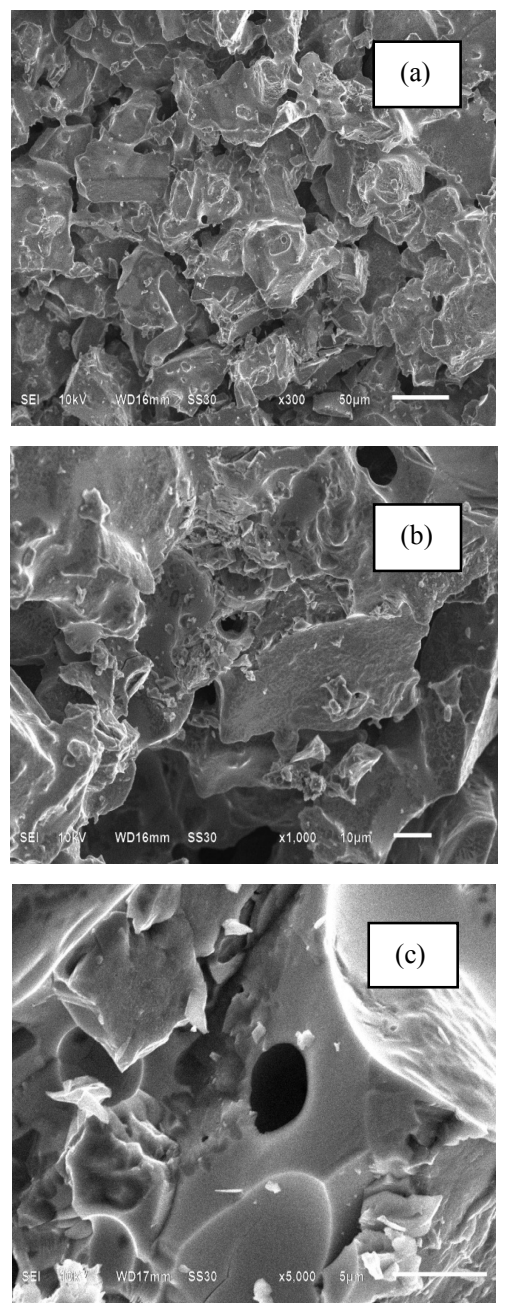

Figure 4. SEM imagines of sample SP2-100. (a) $\times 300$; (b) $\times 1000$; (c) $\times 5000$.

shown in Figures 7 and 8. The peak pores formed in SP4-100 and SP6-100 are at $15.11 \mu \mathrm{m}$ and $13.95 \mu \mathrm{m}$, respectively. The average pore diameters of SP4-100 and SP6-100 are $5.45 \mu \mathrm{m}$ and $5.27 \mu \mathrm{m}$, respectively. The
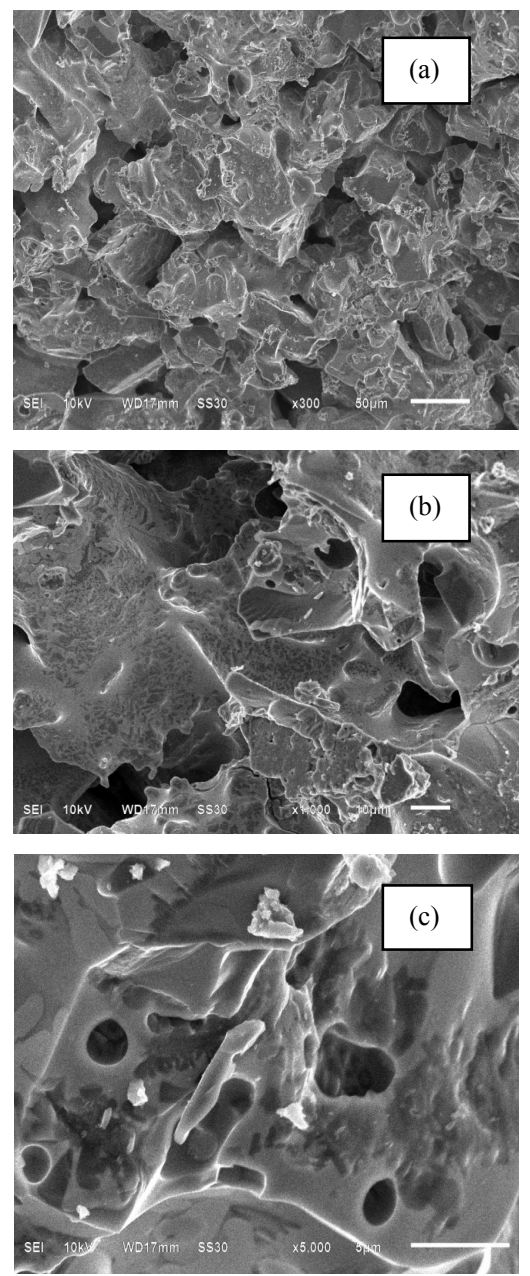

Figure 5. SEM imagines of sample SP4-100. (a) $\times 300$; (b) $\times 1000$; (c) $\times 5000$.

peak pores and the average pore diameters decreased a little with increasing DC249TM silicone resin/SiC mass ratio. Because more DC249TM silicone resin lead to more closely stack of raw material granules. The pore diameters remained mainly between $10 \mu \mathrm{m}$ and $25 \mu \mathrm{m}$ for the both samples. The porosities of SP4-100 and SP6-100 are $39.57 \%$ and $31.95 \%$, and the total pore areas of them are $0.151 \mathrm{~m}^{2} \cdot \mathrm{g}^{-1}$ and $0.134 \mathrm{~m}^{2} \cdot \mathrm{g}^{-1}$, respectively. The porosities and average pore diameters of other samples were presented in Table 1, instead of figures shown here, to avoid too many figures in this manuscript.

\subsection{Thermal Conductivity}

The thermal conductivities of SP2, SP4, and SP6 are listed in Table 1. The thermal conductivities changed from $0.65 \mathrm{~W} \cdot \mathrm{m}^{-1} \cdot \mathrm{K}^{-1}$ to $1.07 \mathrm{~W} \cdot \mathrm{m}^{-1} \cdot \mathrm{K}^{-1}$.

The thermal conductivities increased with increasing molding pressures and DC249TM silicone resin/SiC mass ratio. There are many different values published depending on $\mathrm{SiC}$ ceramic microstructure, composition 

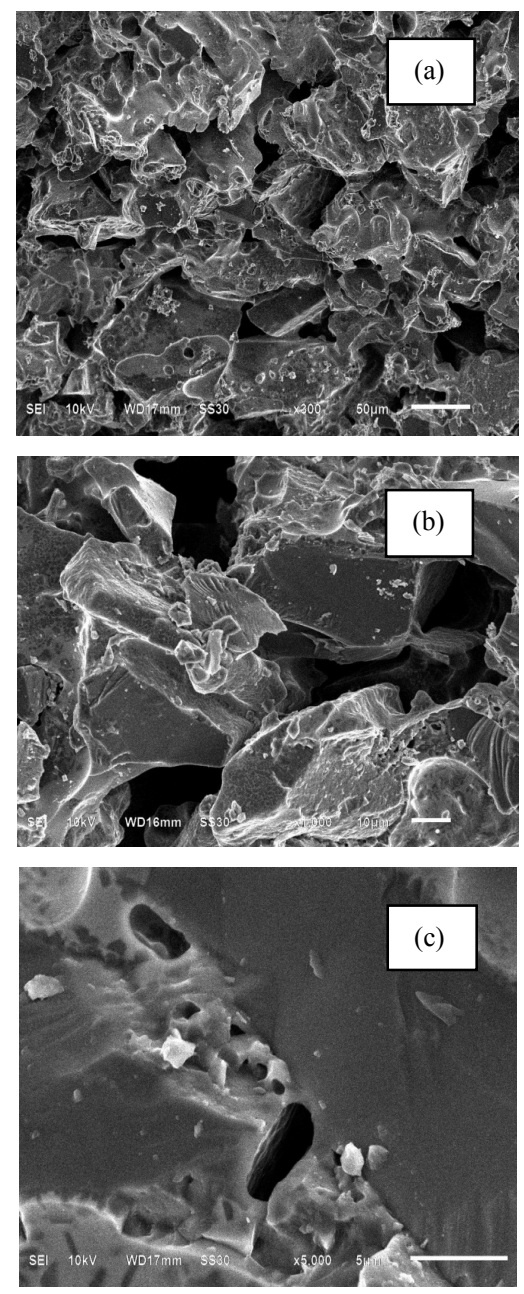

Figure 6. SEM imagines of sample SP6-100 (a) $\times 300$; (b) $\times 1000$; (c) $\times 5000$.



Figure 7. Mercury injection curves of sample SP4-100: (a) Pore distribution curve; (b) Cumulative Pore Area vs Pore size).

and processing method [11,14-16]. But in fact, the main factor to influence the thermal conductivities is the porosity of the samples. The thermal conductivities were increased from $0.68 \mathrm{~W} \cdot \mathrm{m}^{-1} \cdot \mathrm{K}^{-1}$ to $1.03 \mathrm{~W} \cdot \mathrm{m}^{-1} \cdot \mathrm{K}^{-1}$ with

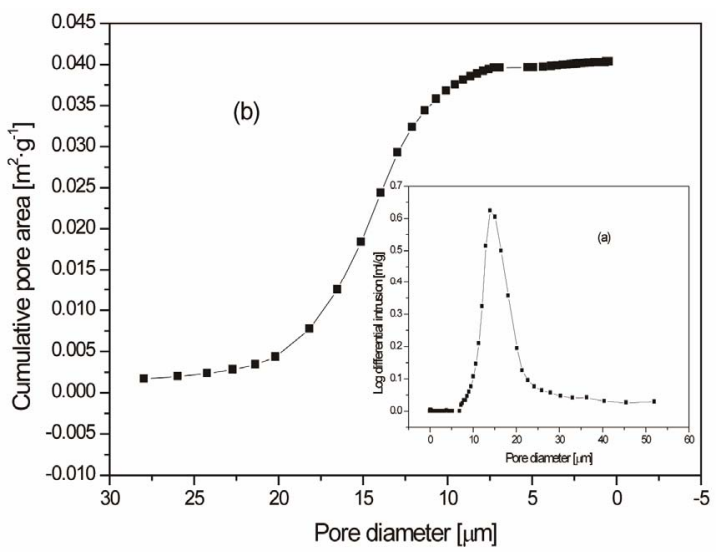

Figure 8. Mercury injection curves of sample SP6-100 (a) Pore distribution curve; (b) Cumulative Pore Area vs Pore size).

the porosity decreasing from $41.96 \%$ to $31.30 \%$, avoiding the molding pressures and the mass ratio factors, and reordering the porosities and thermal conductivities of all the samples in Table 1. And the thermal conductivities were also increased from $0.68 \mathrm{~W} \cdot \mathrm{m}^{-1} \cdot \mathrm{K}^{-1}$ to $1.03 \mathrm{~W} \cdot \mathrm{m}^{-1} \cdot \mathrm{K}^{-1}$ with the average pore diameter decreasing from $5.66 \mu \mathrm{m}$ to $5.21 \mu \mathrm{m}$. This result is reasonable, for higher porosity meaning higher ratio of air phase in samples, and air having low thermal conductivity, ranking only second to vacuum.

\section{Conclusion}

Porous $\mathrm{SiC}$ ceramic were prepared with silicon carbide powder as the aggregate, silicone resin as the binder and pore agent by the process of mixing, iso-static pressure molding, and calcination. The compressive strengths of the samples were between 14.3 MPa and 19.4 MPa. The porosities reached up to $30 \%$, and pore diameters ranged from $5.27 \mu \mathrm{m}$ to $5.45 \mu \mathrm{m}$. The thermal conductivities changed from $0.65 \mathrm{~W} \cdot \mathrm{m}^{-1} \cdot \mathrm{K}^{-1}$ to $1.07 \mathrm{~W} \cdot \mathrm{m}^{-1} \cdot \mathrm{K}^{-1}$, and increased with increasing molding pressures and DC249TM silicone resin/ $\mathrm{SiC}$ mass ratio. The thermal conductivities, mainly influenced by porosities, increased from 0.68 $\mathrm{W} \cdot \mathrm{m}^{-1} \cdot \mathrm{K}^{-1}$ to $1.03 \mathrm{~W} \cdot \mathrm{m}^{-1} \cdot \mathrm{K}^{-1}$ with the porosity decreasing from $41.96 \%$ to $31.30 \%$.

\section{Acknowledgments}

The work was funded by the National Laboratory of Mineral Materials, China University of Geosciences, Beijing, People's Republic of China (grant 06006, H03088 and $\mathrm{H} 03122$ ).

\section{REFERENCES}

[1] M. Käärik, M. Arulepp, M. Karelson and J. Leis, "The Effect of Graphitization Catalyst on the Structure and 
Porosity of Sic Derived Carbons," Carbon, Vol. 46, No. 12, 2008, pp. 1579-1587. doi:10.1016/i.carbon.2008.07.003

[2] P. Pastila, V. Helanti, A.-P. Nikkilä and T. Mäntylä, "Environmental Effects on Microstructure and Strength of Sic-Based Hot Gas Filters," Journal of the European Ceramic Society, Vol. 21, No. 9, 2001, pp. 1261-1268. doi:10.1016/S0955-2219(00)00326-5

[3] J. F. Li, H. Lin and J. B. Li, "Factors That Influence the Flexural Strength of Sic-Based Porous Ceramics Used for Hot Gas Filter Support," Journal of the European Ceramic Society, Vol. 31, No. 5, 2011, pp. 825-831. doi:10.1016/j.jeurceramsoc.2010.11.033

[4] U. Soy, A. Demir and F. Caliskan, "Effect of Bentonite Addition on Fabrication of Reticulated Porous Sic Ceramics for Liquid Metal Infiltration," Ceramics International, Vol. 37, No. 1, 2011, pp. 15-19. doi:10.1016/j.ceramint.2010.07.028

[5] R. J. Ciora, B. Fayyaz, P. K. T. Liu, V. Suwanmethanond, R. Mallada, M. Sahimi and T. T. Tsotsis, "Preparation and Reactive Applications of Nanoporous Silicon Carbide Membranes," Chemical Engineering Science, Vol. 59, No. 22-23, 2004, pp. 4957-4965. doi:10.1016/j.ces.2004.07.015

[6] S. Biamino, A. Antonini, C. Eisenmenger-Sittner, L. Fuso, M. Pavese, P. Fino, E. Bauer and C. Badini, "Multilayer $\mathrm{SiC}$ for Thermal Protection System of Space Vehicles with Decreased Thermal Conductivity through the Thickness," Journal of the European Ceramic Society, Vol. 30, No. 8, 2010, pp. 1833-1840. doi:10.1016/j.jeurceramsoc.2010.01.040

[7] K. Bourenane, A. Keffous, G. Nezzal, A. Bourenane, Y. Boukennous and A. Boukezzata, "Influence of Thickness and Porous Structure of Sic Layers on the Electrical Properties of Pt/SiC-pSi and Pd/SiC-pSi Schottky Diodes for Gas Sensing Purposes," Sensors and Actuators B: Chemical, Vol. 129, No. 2, 2008, pp. 612-620. doi:10.1016/j.snb.2007.09.039

[8] A. Dey, N. Kayal and O. Chakrabarti, "Preparation of Porous Sic Ceramics by an Infiltration Technique," $\mathrm{Ce}$ ramics International, Vol. 37, No. 1, 2011, pp. 223-230.
[9] J. Bai, X. Yang, Y. Shi, S. Xu and J. Yang, "Fabrication of Directional SiC Porous Ceramics Using $\mathrm{Fe}_{2} \mathrm{O}_{3}$ as PoreForming Agent," Materials Letters, Vol. 78, 2012, pp. 192-194. doi:10.1016/i.matlet.2012.03.046

[10] A. Maity, D. Kalita, N. Kayal, T. Goswami, O. Chakrabarti and P. G. Rao, "Oxidation Behavior of SiC Ceramics Synthesized from Processed Cellulosic Bio-Precursor," Ceramics International, Vol. 38, No. 6, 2012, pp. 4701-4706. doi:10.1016/j.ceramint.2012.02.054

[11] N. Popovska, E. Alkhateeb, A. P. Fröba and A. Leipertz, "Thermal Conductivity of Porous Sic Composite Ceramics Derived from Paper Precursor," Ceramics International, Vol. 36, No. 7, 2010, pp. 2203-2207. doi:10.1016/j.ceramint.2010.05.028

[12] K. E. Pappacena, M. T. Jonson, H. Wang, W. D. Porter and K. T. Faber, "Thermal Properties of Wood-Derived Copper-Silicon Carbide Composites Fabricated via Electro-Deposition," Composites Science and Technology, Vol. 70, No. 3, 2010, pp. 478-484.

[13] F. Chen, Y. Yang, Q. Shen and L. Zhang, "Macro/Micro Structure Dependence of Mechanical Strength of Low Temperature Sintered Silicon Carbide Ceramic Foams," Ceramics International, Vol. 38, No. 6, 2012, pp. 52235229.

[14] D. B. Hondongwa, L. R. Olasov, B. C. Daly, S. W. King and J. Bielefeld, "Thermal Conductivity and Sound Velocity Measurements of Plasma Enhanced Chemical Vapor Deposited a-SiC:H Thin Films," Thin Solid Films, Vol. 519, No. 22, 2011, pp. 7895-7898. doi:10.1016/j.tsf.2011.05.014

[15] B. K. Jang and Y. Sakka, "Influence of Microstructure on the Thermophysical Properties of Sintered Sic Ceramics," Journal of Alloys and Compounds, Vol. 463, No. 1-2, 2008, pp. 493-497. doi:10.1016/j.jallcom.2007.09.055

[16] W. S. Yang, S. Biamino, E. Padovano, M. Pavese, S. Marchisio, G. D. Amico, S. Ceresa Mio, X. Chen, P. Fino and C. Badini, "Thermophysical Properties of Sic Multilayer Prepared by Tape Casting and Pressure Less Sintering," Composite Structures, Vol. 96, 2013, pp. 469-475. doi:10.1016/j.compstruct.2012.09.018 